\title{
O MOVIMENTO SOCIAL INDÍGENA E A CONQUISTA DA ESCOLA INTERCULTURAL
}

INDIGENOUS SOCIAL MOVIMENT AND THE CONQUEST OF THE INTERCULTURAL SCHOOL MOVIMIENTO SOCIAL INDÍGENA Y LA CONQUISTA DE LA ESCUELA INTERCULTURAL

\begin{abstract}
Alceu Zoia
Doutorado em Educação pela Universidade Federal de Goiás. Professor Adjunto da Universidade do Estado de Mato Grosso e do Programa de Pós-Graduação em Educação da Universidade do Estado de Mato Grosso. alceuzoia@gmail.com.
\end{abstract}

0000-0002-0512-9511

\section{Luiz Felipe Sousa Curvo}

Mestrado em Educação pela Universidade do Estado do Mato Grosso (2020). Atualmente ocupa o cargo de Bibliotecário-documentalista pelo Instituto Federal de Educação, Ciência e Tecnologia do Maranhão, Campus Barra do Corda. luiz.curvo88@gmail.com.

\section{0-0002-0476-5663}

Correspondência: Fundação Universidade do Estado de Mato Grosso, Campus de Sinop. Av. dos Ingás, $\mathrm{n}^{\circ}$ 3001, Centro. 78550-000 - Sinop, MT - Brasil.

\section{Recebido em: 12.10.2020.}

Aceito em: 20.11.2020

Publicado em: 01.01.2021.

\begin{abstract}
RESUMO:
Movimento sociais tiveram grande participação como agentes políticos ao longo do século $X X$, é dessa articulação a nível de América Latina que ganha força a perspectiva da interculturalidade dentro da educação escolar indígena, que busca assim compreender a escola dentro das desigualdades pós-coloniais. O movimento indígena brasileiro começa a se organizar a partir da década de 70, tendo a União das Nações Indígenas (UNI) grande participação na carta constitucional de 1988, a qual irá fundamentar os direitos educacionais relativos à escola intercultural inserida dentro de um projeto societário próprio.
\end{abstract}

PALAVRAS-CHAVES: Movimentos sociais. Educação intercultural. Povos indígenas.

\section{Introdução}

É a partir da atuação indígena organizada enquanto movimento social, em ação articulada também sob a ótica do contexto da América Latina, que emergem os anseios políticos, culturais e educacionais que irão se fazer presente na concepção de escola intercultural, que tem por princípio o protagonismo indígena.

Um marco que representa a superação legal da ideia de assimilação dos povos indígena e a reafirmação do direito a uma educação escolar que valorize a diversidade cultural e o projeto societário de cada povo, é a carta constitucional de 1988, que contou com decisiva participação do movimento indígena.

Assim a escola, historicamente utilizada como forma de doutrinação e assimilação do indígena dentro de um processo de desterritorialização e negação de sua cultura, revela-se importante instrumento de valorização da identidade étnica e cultural.

\section{Desenvolvimento}

O século XX viu florescer no Brasil e na América Latina diversos movimentos sociais ligados às lutas populares. Sob o clima da Declaração dos Direitos Humanos de 1948 que reconhecia direitos e liberdades, era emergente uma série de bandeiras e reivindicações relacionadas a identidades étnicas e minorias culturais. A nível 
internacional é no ano de 1975 que pela primeira vez na história do movimento indígena, povos originários de 19 nacionalidades se reuniram no Canadá para discutir problemas que lhes atingiam e formas de organização para a definição de estratégias de enfrentamentos dessas questões levantadas. (BICALHO, 2010).

Na América Latina, segundo Fleuri (2003, p. 20), "a diversidade cultural foi historicamente relegada e deixada à margem das propostas e práticas educativas que, a exemplo do que ocorreu na Europa, se pautaram no ideal homogeinizador do EstadoNação". As políticas educacionais foram, portanto, formadas a partir desse ideal de uma cultura única na formação primordial dessas políticas nos países latino-americanos, que tinham, como uma de suas consequências, o baixo rendimento escolar de estudantes que tinham como língua materna uma diferente da utilizada nos sistemas oficiais de ensino. Para Fleuri (2003), movimentos ligados à cultura popular e à educação popular começaram a surgir nos anos 1950, sendo silenciados e submetidos a controles rigorosos a partir da ditadura militar. Esses movimentos voltam a ganhar força nos anos 1970 , quando emergem diversos movimentos (de indígenas, de negros, de homossexuais, de mulheres) que questionavam, a partir de sua identidade, os planos econômicos e políticos vigentes, levando o debate a variadas concepções das relações socioculturais dos processos identitários, caracterizadas como interculturais.

Para Fleuri (2003), a concepção de educação intercultural ganha força a partir da sua dimensão político-pedagógica em superação à perspectiva bi-cultural, ou multicultural. Segundo o autor (2003, p. 21), a "interculturalidade, além de expressar a coesão étnica de um grupo social, proporcionando condições para o fortalecimento da identidade cultural, vai também estimular a aquisição do conhecimento cultural dos outros povos". Essa nova conceituação acarretou numa grande mudança no tratamento das diferenças culturais dentro do ambiente escolar, relacionada à emergência das identidades indígenas na luta por seus direitos. Revoltas indígenas ocorridas no México, Bolívia, Equador, Chile, Colômbia, Brasil, entre outros, buscavam o direito de posse sobre suas terras e consequentemente revalorização de suas línguas e tradições, o que exigia programas educativos adequados a esta realidade. Fleuri $(2003$, p. 22) caracteriza como "uma nova perspectiva epistemológica que aponta para a compreensão do hibridismo e da ambivalência, que constituem as identidades e relações interculturais". Para Fleuri (2003, p. 23):

A intercultura vem se configurando como um objeto de estudo interdisciplinar e transversal, no sentido de tematizar e teorizar a complexidade (para além da pluralidade ou da diversidade) e a ambivalência ou o hibridismo (para além da reciprocidade ou da 
evolução) dos processos de elaboração de significados nas relações intergrupais e intersubjetivas, constitutivos de campos identitários em termos de etnias, de gerações, de gênero e de ação social.

As culturas originárias não são subalternas aos movimentos hegemônicos, e como é possível reconhecer na globalização e na contemporaneidade, elas resistem e se afirmam por meio de movimentos sociais indígenas. É importante compreender que o processo de trocas culturais não torna estes povos menos indígenas. Muitos povos ao longo do contato se inclinaram favoráveis a dominar técnicas e conhecimentos outros que adentraram o continente ameríndio por meio do colonialismo ocidental, nem por isso renegando sua identidade étnica e seus conhecimentos tradicionais. Segundo Favre (1998), o próprio indigenismo deve ser entendido não como uma pura expressão do pensamento indígena, mas uma reflexão eminentemente sincrética de uma resistência gerada neste contato.

\begin{abstract}
El movimiento indigenista no es la manifestación de un pensamiento indígena, sino una reflexión criolla y mestiza sobre El índio [...]. Esto no impide que tome decisiones acerca de su destino en sus propios lugares, según los intereses superiores de la nación tal y como son concebidos por los indigenistas. Eso es precisamente lo que reprocha El indianismo, desarrollado a partir del decenio de 1970, el cual pretende ser la expresión de aspiraciones y reivindicaciones auténticamente índias. Por el eco que tiene actualmente en el conjunto de la sociedad, la critica radical a la que el indigenismo es sometido por las organizaciones indianistas manifiesta el derrumbamiento de la coyuntura en la que aquél se expandió (FAVRE, 1998, p. 11).
\end{abstract}

Partindo de Bergamaschi (2014), é considerada uma compreensão do indígena enquanto produtor de conhecimento científico, uma compreensão que não hierarquiza as constituições da cultura, estabelecida pelo vivenciar intercultural que é também de natureza ética. Como a ciência não está livre das disputas ideológicas e utópicas relacionadas aos seus resultados é preciso que estes intelectuais, representantes de seus movimentos sociais, interfiram no estado em questão, pois a ciência serva ao capitalismo busca o aumento da produção e seu barateamento de forma a garantir maiores lucros e a expansão de seus mercados. É preciso contrapor essa epistemologia pró-capital e pensar a ciência não para a plena exploração de um planeta limitado, mas para que haja um equilíbrio com a natureza preservada, para que as culturas tradicionais possam exercer sua liberdade. Segundo Passos (2010, p. 28):

A mercadoria incidiu sobre a vida dos seres humanos, agora destituídos de sua liberdade e autodeterminação, em favor do mercado que se torna vivo e tem a palavra da ordem da vida e da morte dos seres humanos, induzindo-os a pura reprodução material de sua existência, 
expropriados que foram por uma cultura da dominação que minou a liberdade deles.

Decorre disto uma percepção epistemológica de que a função da escola nas sociedades indígenas seja o de assimilar essa população e adaptá-la frente à cultura hegemônica em sua obsessão pela produção e acumulação material. Silva e Herbetta (2017) apontam para uma necessidade de uma nova base epistêmica que contemple a reflexão sobre o acesso, permanência e formação do indígena, que não recorram ao erro de impor valores eurocêntricos, reproduzindo a dinâmica de integração dos indígenas à sociedade ocidental.

Para Bicalho (2010), diante de uma América Latina que apresentava governos autoritários e frágeis estruturas democráticas, a conquista de direitos pelos indígenas se mostrava difícil de ser alcançada, ainda mais se considerando a pouca articulação de um Movimento Indígena ainda por se construir em meados do século XX. No curso da Ditadura Militar, que perdurou de 1964 até o ano de 1985, a ideia de índio era vista de maneira transitória, um empecilho ao progresso nacional. Neste momento autoritário da história do país, apoiar as demandas indígenas por seu território e sua cultura era visto como um ato de subversão. A ditadura teve como política de integração nacional a criação de reservas para remover os indígenas de suas terras originais.

Segundo Bicalho (2010), no Brasil, um marco fundador do Movimento Indígena pode ser considerado as Assembleias Indígenas, organizadas pelo Conselho Indigenista Missionário (CIMI) que tiveram a oportunidade de reunir diversas lideranças indígenas de povos que abrangiam uma grande distância geográfica entre si. Etnias que sem o auxílio e financiamento do CIMI, não teriam a possibilidade de se encontrar. Tem-se assim o ano de 1974 como o ano da primeira Assembleia Indígena ocorrida em Diamantino-MT, dois anos após a criação do CIMI, onde compareceram as etnias Bororo, Xavante, Apiaka, Kaiabí, Rikbaktsa, Iranxe, Pareci e Nambikwara. As Assembleias são espaços onde pela primeira vez os contatos interétnicos permitiram uma percepção enquanto coletividade na luta por reconhecimento, proporcionando uma maior disposição para a resistência na atuação social, o que passou a incomodar as diretrizes do Regime Militar. "Onde os indígenas raramente apareciam como sujeitos históricos, mas apenas como seres em extinção ou em fase de integração rumo à comunidade nacional -, os índios teriam conseguido tornar pública a sua versão do Brasil através das Assembleias" (BICALHO, 2010, p. 157).

Sendo um organismo vinculado à Conferência Nacional dos Bispos do Brasil (CNBB), o CIMI teria criado espaços de articulação a partir de um tipo de associação panindígena, que tinha por objetivo a autodeterminação destes povos. Essa nova atuação 
da Igreja Católica por meio do CIMI é fruto de seu reconhecimento em relação a políticas de evangelização equivocadas desde os tempos coloniais, e desta forma, a partir de mudanças concretizadas no Concílio Vaticano II realizado de 1962 a 1965 a Conferência Geral do Episcopado Latino-Americano se reuniu em Medellín na Colômbia, buscando a partir daí um novo diálogo com os povos indígenas que tinha por inspiração a Teologia da Libertação (BICALHO, 2010).

Segundo Cunha (2012), na década de 1970 surgiram inúmeras novas organizações indígenas e não indígenas em apoio às causas dos povos indígenas. Na década seguinte os indígenas conseguem se mobilizar e organizar frentes de atuação de âmbito nacional, o que se revelou fundamental para a grande virada histórica que representa os direitos conquistados na Constituição de 1988 que finda legalmente a visão assimilacionista afirmando aos indígenas seus direitos históricos, inclusive à posse da terra.

Dois momentos em que a articulação indígena foi posta a prova foram em 1978, na tentativa de emancipação dos índios por Decreto e em início dos anos 80 quando a FUNAI designou a si contestáveis maneiras de estipular quem é e quem não é indígena. "A relação com a FUNAI é de extrema indisposição. As falas indígenas são quase unânimes ao se posicionarem sobre a Fundação, o que denota uma total descrença quanto aquele que 'é o órgão principal, encarregado de nossas questões" (BICALHO, 2010, p. 166). É neste contexto que em 1980 surge a União das Nações Indígenas (UNI), primeira organização nacional de fato indígena, o que desagradou a FUNAl, que não reconhecia o direito à organização fora de sua tutela. De acordo com Bicalho (2010, p. 144):

\begin{abstract}
A UNI [...] surgiu como uma organização indígena amplamente apoiada pelo CIMI, entre outras organizações de apoio, e incomodou muito o Regime por trazer à tona questões incompatíveis com a ideologia integracionista posta em prática pelo Governo: autonomia cultural, nações indígenas, autodeterminação, representatividade política, atuação de lideranças, movimento indígena, etc. Nota-se que o próprio Governo temia que a legalização da UNI conduzisse à perda de funcionalidade da FUNAI e ao crescimento do MIB [Movimento Indígena Brasileiro].
\end{abstract}

A autora destaca a participação da União das Nações Indígenas (UNI) na Assembleia Nacional Constituinte, que pôde acompanhar de perto os trâmites da Subcomissão dos Negros, Populações Indígenas, Pessoas Deficientes e Minorias no Congresso, onde se entendeu a necessidade de um discurso unificado entre as lideranças e organizações indígenas. Com seus cocares, flechas e ritos simbólicos, os indígenas ocupavam também outros espaços de discussões, como a Subcomissão de Educação, 
cultura e esporte contando com o auxílio de organizações indigenistas como o CIMI e a Associação Brasileira de Antropologia (ABA) onde apontavam a necessidade de uma educação diferenciada que respeitasse suas tradições culturais. Os ideais integracionistas eram em 1987 ainda muito presentes, neste contexto temos o célebre discurso de Aílton Krenak, então um dos coordenadores da UNI, que ao pintar o rosto de jenipapo em plenário, alcançou o reconhecimento da opinião pública o que se tornou decisivo para que as demandas indígenas fossem aprovadas no texto final da Constituição. Esse momento representa uma grande virada na história do Brasil onde finalmente os direitos indígenas eram reconhecidos oficialmente pelo Estado Nacional.

Para Bicalho (2010), as políticas indigenistas se tratam de uma atuação de origem governamental junto às comunidades indígenas enquanto as políticas indígenas se tratam de formas de atuação elaboradas pelos próprios indígenas e suas lideranças. Uma reivindicação unânime foi a necessidade de demarcação das terras. "Até porque é preciso lembrar que o território caracteriza o vínculo diferenciado que têm com a terra e é essencial para a sobrevivência física e cultural desses povos" (BICALHO, 2010, p. 172). Os problemas com a terra são de vários tipos, terras já demarcadas constantemente invadidas por fazendeiros ou posseiros, terras ainda sem demarcação, terras invadidas e desmatadas para criação de gado, extração de madeira, minérios, etc. Neste contexto, a reivindicação da terra era a principal bandeira, entretanto a luta pela educação tinha lugar de destaque também. Se esse processo histórico representava uma tênue negociação entre a democracia e autoritarismo, é justamente por essa oposição que o Movimento Indígena permanece após essa conquista, no sentido da luta pelo cumprimento da legislação.

Assim, a Constituição de 1988, e principalmente a atuação durante a Constituinte, se tornaram marcos simbólicos do poder de articulação do Movimento Indígena. "Chegar a esses textos constitucionais favoráveis às populações indígenas - por séculos dominados e explorados por Estados nacionais que enalteciam projetos identitários homogeneizantes - não foi tarefa fácil" (BICALHO, 2010, p. 178).

Complementa Bicalho (2010, p. 173):

A consciência do direito à educação também aparecia em algumas falas, já reconhecendo inclusive a importância do estudo para o alargamento de suas atuações junto ao Estado e a sociedade nacional. Dessa percepção, subjaz o protagonismo indígena na luta pelos seus direitos, e que na atualidade se tornou tão evidente. Apesar daqueles que ainda viam na formação estudantil uma forma de afastamento do índio da sua aldeia, da sua cultura, como o índio Urébépté, havia também os que acreditavam que além da terra, "o índio deve querer estudar", para poder lutar pelas suas terras, pelas suas famílias, pelos 
seus direitos com mais autonomia e segurança, ou ainda, "para que eles possam nos defender no futuro.

A Constituição de 1988 é uma grande virada na história iniciada no contato entre povos indígenas e os invasores europeus. Finalmente os direitos indígenas eram reconhecidos oficialmente pelo Estado Nacional. Para Zoia (2010), é apenas a partir de uma ressignificação resultante dos direitos conquistados na Constituição de 1988, na formalização do direito a um projeto societário próprio que a escola irá se inserir no coração da sociedade indígena. Segundo Zoia (2010, p. 70):

O caminho da educação escolar indígena em sua singularidade é a esperança dos povos indígenas para conquista definitiva dos seus direitos e de sua terra, tendo como referencial a autonomia e sua luta na construção de uma política indígena na educação escolar, que enfatize a formação e a valorização da sua cultura e práticas educacionais.

Para Bicalho (2010), reconhecer o índio como detentor de direitos coletivos e de cidadania, significa contrapor um ideal de sociedade que privilegia os direitos do indivíduo. A diferença aqui destoa da razão iluminista materializada na Declaração Universal dos Direitos do Homem. Para Bicalho (2010, p. 233):

Os Estados nacionais que, como o Brasil, ao longo de suas histórias negaram as diferenças, começaram a mudar justamente após a Segunda Guerra. As décadas subseqüentes propunham um novo paradigma no qual as diferenças étnicas, de gênero, sociais, sexuais e religiosas tornaram-se bandeiras de luta de vários movimentos em torno do reconhecimento da diversidade e do respeito às diferenças.

Em 2007, a ONU publicou A Declaração das Nações Unidas Sobre o Direito dos Povos Indígenas, reafirmando como parâmetro global, o direito das populações indígenas a um sistema educacional autônomo, ao direito a todas as formas de educação oferecidas pelo Estado, sem discriminação, além do direito do indígena a estabelecer meios de informação próprios além da garantia de acesso à informação não-indígena. Para Bicalho (2010), a Constituição de 1988 junto a Convenção nº 169 da Organização Internacional do Trabalho (OIT) e a Declaração dos Povos Indígenas da ONU trouxeram grandes avanços em relação aos direitos econômicos, sociais e culturais dos índios a nível internacional. De vital importância, afirmam o direito a educação e a informação, ao território e a cultura.

De acordo com Gallois (2016), a busca por uma forma autêntica de tornar a escola indígena foi tema debate entre indígenas, educadores e antropólogos no Seminário 
Políticas culturais e povos indígenas: a escola e outros problemas realizado no ano de 2013. Os não-indígenas pareciam ter críticas mais radicais quanto à escolarização e as ideias de interculturalidade que os próprios indígenas na relação entre a escola e os conhecimentos tradicionais. Aos indígenas interessava uma análise mais concreta de seus problemas reais de formação, acesso, permanência, etc.

A partir da percepção da escola enquanto ferramenta poderosa na resistência cultural dos povos indígenas, Munduruku (2017) reconhece avanços relativos à educação escolar indígena no sentido de que a formação de professores indígenas possa contribuir para uma concepção pedagógica autônoma entre os povos. Nas palavras do intelectual indígena Daniel Munduruku (2017, p. 3):

Entendo que há uma preocupação prática nos diversos programas de educação indígena espalhados pelo Brasil afora, sejam eles operados pelas esferas governamentais ou não-governamentais. Muitos desses programas têm partido do princípio que é preciso fortalecer a autoria como uma forma de fortalecer também a identidade étnica dos povos que atendem. Isso é muito positivo se a gente entender que a autoria, aqui defendida, signifique que estes povos possam num futuro próximo, criar sua própria pedagogia, seu modo único de trafegar pelo universo das letras e do letramento. Só assim posso imaginar que valha a pena o esforço dos que se põem a trilhar este caminho. Se estes grupos de fato acreditarem que estão criando pessoas para a autonomia intelectual e se abrirem espaço na sociedade para a livre expressão deste pensamento, então eles estarão, realmente, fortalecendo a autoria e apresentando um caminho novo para as manifestações culturais, artísticas, políticas, lúdicas e religiosas dos nossos povos indígenas. Caso contrário, estarão levando nossa gente para o mesmo buraco em que o pensamento quadrado ocidental se meteu e, neste caso, estarão sendo piores que o regime ditatorial que almejava exterminar as identidades transformando-as numa única e cínica identidade nacional brasileira.

Se nos primeiros séculos do contato cultural a escola foi inserida dentro das comunidades indígenas como uma instituição estranha, desconexa com a cultura local e etnocida em sua missão de cristianizar os povos indígenas, hoje ela é ferramenta poderosa para a própria preservação de sua cultura tradicional. Essa contradição seria inerente à educação escolar, "a escola é percebida ao mesmo tempo como instrumento de empoderamento para a 'autonomia' e também como uma armadilha para a domesticação de conhecimentos" (GALLOIS, 2016, p. 509). Um dos efeitos da apropriação da cultura no contexto da educação escolar é "fazer delas [escolas] um espaço para o exercício da política indígena, que consiste inclusive em aprender a política dos brancos, para daí participar mais ativamente do movimento indígena" (GALLOIS, 2016, p. 512). 
O etnocídio presente na ideologia de integração dos povos indígenas à ordem mercantilista e cristã do ocidente é representado em uma concepção de educação supostamente redentora do atraso civilizatório dos povos indígenas. Assim denuncia Munduruku (2017), pois aponta que esta educação teria como objetivo final destruir a identidade étnica indígena e dar ao capital o domínio sobre suas terras. Afirma o autor que o ser ocidental compreende a natureza como externa a ele, ignorando a sua escrita ao tentar apoderar-se dela. Esta ideia está inserida numa lógica de dominação do europeu e em como este impôs sua visão de mundo a partir da dominação colonial. Segundo Munduruku (2017, p. 2-3):

\begin{abstract}
Foi-se criando uma necessidade nos jovens nativos de apreender conceitos e teorias que não cabem no pensar holístico e circular de seus povos. Esta agressão ao sistema mental indígena, fruto de uma história da qual não somos culpados, mas sobre qual temos responsabilidade, acaba se perpetuando nas novas políticas inclusivistas levados a efeito por governos nas três esferas. Conclusão: nossos jovens se vêm obrigados a aceitar como inevitável à necessidade de ler e escrever códigos das quais prefeririam não aprender e não lhes é dado o direito de recusar sob a acusação de preguiça ou descaso para com a 'boa vontade' dos governos e governantes.
\end{abstract}

A escola que tem o indígena por protagonista e os conhecimentos que nela serão ensinados emergem da importante atuação dos movimentos sociais indígenas. Para Zart (2012, p. 25), "os conhecimentos [são] como processos dinâmicos, e, socialmente os grupos definem a verossimilhança dos conhecimentos, isto é, o conhecimento é verdadeiro na relação social, e não numa pré-definição", definindo assim o conhecimento como historicamente construído dentro de relações simbólicas presentes nas formas de linguagem. "[...] o conhecimento é o que os atores sociais definem como sendo verdadeiro, válido e que será legitimado e socialmente aceito" (ZART, 2012, p. 25). Uma realidade assim eminentemente política e cultural. Prossegue Zart (2012, p. 25) "[...] definir socialmente a realidade que foi construída é admitir relações sociais que demonstram não somente a diversidade das sociedades, mas ilustram também as suas contradições e arbitrariedades, portanto, as desigualdades sociais".

Passos (2010) atenta também a este caráter político da educação, ao associar a resistência à luta por direitos dos indígenas em seu reconhecimento de si enquanto grupo heterogêneo. "A revolta é um símbolo de luta, sobretudo quando nasce da descoberta da injustiça, e que necessita para além do instinto de classe a consciência de classe" (PASSOS, 2010, p. 34). Nas discussões que envolviam antropólogos e indígenas, a necessidade de uma educação bilíngüe e a atenção à saúde do indígena era constantemente levantada. A escola dita intercultural era vista como essencial na 
apropriação dos direitos culturais e históricos dos indígenas (BICALHO, 2010). A cena política nacional tinha o indígena "como um novo ator político e social, que começou a organizar politicamente, consciente da sua cultura, da sua história, dos seus direitos e da necessidade de mobilização do grupo como meio de ruptura com a condição de colonizado". (BICALHO, 2010, p. 174).

A escola ressignificou-se a partir da concepção do direito a um projeto societário baseado em sua autonomia e protagonismo buscando assim o estado brasileiro, atuar na formação de professores indígenas que possam ensinar em sua língua originária. Essa posição da escola na sociedade indígena está ligada ao reconhecimento do direito indígena à sua cultura e na compreensão de que as políticas públicas devem ser fundamentadas na autonomia e protagonismo do indígena. Para Zoia (2010) a escola se tornará fundamental no processo de valorização e preservação da cultura indígena, atuando na emancipação destes povos frente à ordem cultural hegemônica. $O$ resultado disso é o fortalecimento, por exemplo, da língua, onde a educação escolar se torna instrumento de reafirmação da língua ancestral. Segundo Zoia (2010, p. 70):

O caminho da educação escolar indígena em sua singularidade é a esperança dos povos indígenas para conquista definitiva dos seus direitos e de sua terra, tendo como referencial a autonomia e sua luta na construção de uma política indígena na educação escolar, que enfatize a formação e a valorização da sua cultura e práticas educacionais.

Este significado e sentido é destacado por Zoia (2010), pois como indica o pesquisador, muitas comunidades indígenas passaram a visualizar na escola um espaço propício tanto ao acesso à conhecimentos gerais decorrentes das necessidades póscoloniais, quanto na valorização dos conhecimentos historicamente construídos, um espaço que seria constituído a partir das especificidades culturais de cada povo em sua afirmação étnica.

\section{Conclusão}

A partir das leituras realizadas por meio da pesquisa bibliográfica, percorreram-se questões de suma importância para a educação escolar indígena no Brasil, da organização enquanto movimento até a conquista de direitos dos quais se fundamentava a importância da escola intercultural nas comunidades indígenas. A história dos indígenas no Brasil é uma história de violência, de genocídio, etnocídio e epistemicídio, mas também de grande resistência cultural que já dura mais de cinco séculos. Tem como um novo paradigma, na relação com a sociedade envolvente e o 
estado nacional brasileiro, a atuação do movimento indígena organizado a nível nacional manifesta na carta constitucional.

A educação intercultural representa uma possibilidade de ressignificação em relação à escola junto aos povos indígenas, podendo representar um instrumento de empoderamento social, cultural e político. Apesar desses avanços, é importante considerar a situação de marginalização ao qual caracteriza de forma geral a situação dos indígenas no continente americano pós-colonial. Estão os povos indígenas ainda muito sub-representados nas instâncias políticas representativas, e seus direitos conquistados a duras penas convivem com constantes ameaças oriundas de diversos interesses socioeconômicos.

\section{Referências}

BERGAMASCHI, Maria Aparecida. Intelectuais indígenas, interculturalidade e a educação. Revista Tellus, Campo Grande-MS, ano 14, n. 26, jan./ jul. 2014.

BICALHO, Poliene Soares dos Santos. Protagonismo indígena no Brasil: movimento, cidadania e direitos (1970-2009). 2010. Tese (Doutorado em História). Instituto de Ciências Humanas, Departamento de História, Universidade de Brasília, Brasília, 2010.

CUNHA, Manuela Carneiro da. Índios no Brasil: história, direitos e cidadania. São Paulo: Claro Enigma, 2012.

FAVRE, Henry. El indigenismo. México: Fondo de Cultura Económica, 1998.

FLEURI, Reinaldo Matias. Interculturalidade e educação. Revista Brasileira de Educação, n. 23. 2003.

GALLOIS, Dominique Tilkin. A escola como problema: algumas posições. In: CUNHA, Manuela Carneiro da; CESARINO, Pedro de Niemeyer. (Orgs.). Políticas culturais e povos indígenas. São Paulo: Unesp, 2016.

MUNDURUKU, Daniel. A escrita e a autoria fortalecendo a identidade. 2017. Disponível em:

https://pib.socioambiental.org/pt/A_escrita_e_a_autoria_fortalecendo_a_identidad e. Acesso em: 03 out. 2020.

PASSOS, Luiz Augusto. Cultura: flecha humana e cósmica que aponta o caminho para os sentidos. IN: GRANDO, Beleni Saléte; PASSOS, Luiz Augusto. (Orgs.). O eu e o outro na escola: contribuições para incluir a história e a cultura dos povos indígenas na escola. Cuiabá: EdUFMT, 2010.

SILVA, Maria do Socorro Pimentel da; HERBETTA, Alexandre. Educação intercultural e interepistêmica: desafios políticos para (e a partir) da escola indígena. In: LANDA, 
Mariano Baéz; HERBETTA, Alexandre Ferraz. (Orgs.). Educação indígena e interculturalidade: um debate epistemológico e político. Goiânia: Imprensa Universitária, 2017.

ZART, Laudemir Luiz. Produção social do conhecimento na experiência do curso de agronomia dos movimentos sociais do campo (CAMOSC): interação da Unemat e de movimentos sociais do campo. 2012. Tese (Doutorado em Política Científica e Tecnológica). Instituto de Geociências, Universidade Estadual de Campinas, Campinas-SP, 2012.

ZOIA, Alceu. A questão da educação indígena na legislação brasileira e a escola indígena. IN: GRANDO, Beleni Saléte; PASSOS, Luiz Augusto. (Orgs.). O eu e o outro na escola: contribuições para incluir a história e a cultura dos povos indígenas na escola. Cuiabá: EdUFMT, 2010. 


\section{arevisto Observatório}

\begin{abstract}
:
Social movements had great participation as an agent of political changes throughout the 20th century, it is from this articulation (especially in Latin America) that the perspective of interculturality strengths in the indigenous school education, which seeks to understand the school within the post-colonial inequalities. The Brazilian Indigenous Movement began to organize itself in the 1970s, with the Union of Indigenous Nations (UNI) playing a major role in the 1988 constitutional charter, which will underpin the educational rights related to the intercultural school within a specific social Project.
\end{abstract}

KEYWORDS: Social movements. Intercultural education. Indigenous peoples.

\begin{abstract}
RESUMEN:
Los movimentos sociales tuvieron gran participación como agentes políticos a lo largo del siglo $\mathrm{XX}$, es a partir de esta articulación a nível latinoamericano que la perspectiva de la interculturalidade cobra fuerza dentro de la educación escolar indígena, que busca entender la escuela dentro de las desigualdades poscoloniales. El movimiento indígena brasileño comenzó a organizarse en la década de 1970, con la Unión de Naciones Indígenas (UNI) jugando um papel principal en la carta constitucional de 1988, que sustentará los derechos educativos relacionados con la escuela intercultural dentro de un proyecto social específico.
\end{abstract}

PALABRAS-CLAVES: Movimientos sociales. Educación intercultural. Población indígena. 